\title{
Research on the Optimization of Curriculum System of Logistics Engineering Major Under Internet + Background
}

\author{
Yun-Feng ZHANG ${ }^{1, a}$, Si-Qi ZHANG ${ }^{1, b}$ and Qian-Qian SHAO ${ }^{1, c}$ \\ ${ }^{1}$ School of Transporation Engineering, Shenyang Jianzhu University, LiaoNing, ShenYang, China \\ ayunfengzhang2004@163.com, b2514327624@qq.com, ‘308977035 @qq.com \\ *Qian-Qian SHAO
}

Key words: Logistics engineering, Training scheme, Curriculum system, Practical teaching

\begin{abstract}
The Professional orientation of logistics engineering major under the Internet + background is determined first, then the training scheme is amended on the base of it. The curriculum system and the practical teaching scheme are programmed according to the cultivating goals and training programs.
\end{abstract}

\section{Introduction}

Premier li keqiang pointed out on April 6, 2016, when chaired a state council, that the implementation of the "Internet + circulation " action will be the important measures for promoting the circulation revolution, public business and the public entrepreneurship innovation, it will make for the cost decreasing and benefit for consumption increasing and employment boosting. Under the Internet + circumstance, and with the development of smart technology, the concept of smart logistics personnel training, keeping up with the trend of the history, is put forward. It is accord with the development of modern logistics industry and the new tendency of the development of intelligent control, and also conforms to the trend of the development of the Internet of things.

Under internet + background, in order to make logistics engineering talents to be better and to meet the needs of society, many colleges and universities have conducted a series of reform and exploration on the logistics personnel training, including the construction of the professional training mode, practice teaching and teaching mode, etc. Fu Peihua, Professor of Zhejiang commerce and industry university, probed the professional construction problem of logistics management major under the Internet + background, he put forward the professional group construction in combination of management and engineering with a system view, and taked the construction of guidance of engineering certification background into account. The training goal and training mode is then determined, and the curriculum system and cultivating path is programmed on the base of it[1]. Professional Zhou xiaoguang discussed the talent cultivation practice teaching new mode under Internet + logistics. He Put forward to promoting the university-enterprise cooperation, and construct the innovative type electrical business logistics training base based on campus logistics center[2]. To cultivate students' ability to design, analyze, develop and operate the system, it is needed to promote the combination of industry-university research and research on carrying out practice exercises, internships and innovation and entrepreneurship. The thesis takes intelligent logistics personnel training under the internet + background as the target and the core, explores the intelligent logistics talent training program, curriculum system and practical requirement etc. The study is carried out under the guide of system theory, and will be programmed through systematic planning, implementation and evaluation[3,4]

\section{Analysis of Students' Ability in Logistics Engineering}

The mart talent cultivation of logistics engineering specialty should be based on the professional competence structure system as its fundamental core and starting point. Logistics engineering major is a new frontier subject, its development depends on the many subjects that has the feature of engineering. So the training of the professionals lays emphasis on the ability of logistics system 
planning and logistics information system development. Logistics engineering professional talent should has the ability to solve the logistics system operation, construction and management $[5,6]$. With the consideration with the internet + background in the cultivation of logistics engineering specialty, the ability structure will be adjusted. The intelligent logistics will put new requirement for the professional ability of logistics talents, such as the ability to turn data into products, collaborative decision-making ability etc. The abilities could be sumed up the following points.

\section{Comprehensive Analysis Ability of Logistics System}

System analysis is the base to solve the problem of logistics system. When taking the system analysis, the basic concepts of mathematics and natural science can be applied to the complex logistics system, which can be expressed, modeled, reasoning and parsed. Persons who take the system analysis should be able to carry out the identification and expression of logistics engineering related discipline problems and practical problems of complex logistics engineering, and can correctly describe the solution of a logistics engineering problem, analyze its rationality, and get the effective conclusion etc.

\section{Ability to Solve Complex Logistics Problems}

Logistics engineering students should have the abilities of logistics system planning and designing, the abilities of logistics information system development and application, and the abilities of modern logistics equipment management and maintenance.To complex logistics engineering problem, can carry on the reasonable analysis based on the engineering background, can use the appropriate technology, resources and modern engineering means and information technology tools, to predict, simulate the complex logistics engineering problems, and propose solutions to them.Be able to scientifically evaluate the impact of logistics engineering practices and complex logistics engineering solutions on social, environmente, and social sustainable development, and to understand the responsibilities that should be undertaken.

\section{Ability to Solve the Problem of Intelligent Logistics System}

Intelligent logistics is a system that is supported by information technology, it can realize self adjustment and timely treatment in the logistics transportation, warehousing, packaging, loading and unloading handling, circulation processing, distribution, information service and so on. Intelligent technology enables the logistics system to imitate human intelligence, with the ability of thinking, perception, learning, reasoning judgment and solving certain problems in logistics. With the intelligent trend of logistics system, the ability of data-aware and the big-date processing power will be the basic skills of logistics engineering students should have.

\section{Teamwork and Organization and Management Skills}

Students majoring in logistics engineering should have the humanistic social science literacy and social responsibility to understand and comply with the engineering ethics and norms in engineering practice and fulfill their responsibilities. Have the ability to take on the role of individuals, team members and principals in a multi-disciplinary team.Be able to communicate effectively with industry peers and members of the community on complex engineering issues, such as writing reports and designing documents, presentation of statements, clear expression or response instructions. Have a certain international vision, and can communicate in cross-cultural context. Have self-learning and lifelong learning awareness, and have the ability to continuously learn and adapt to development.

\section{Programming of Curriculum System}

The logistics engineering curriculum system should be able to meet the needs of the target of professional competence training, which is always systematic, dynamic and scientific. The design of curriculum system should focus on the training of engineering ability, innovative spirit and 
professional ability of logistics engineering, and the whole course system will be integrated and developed into an organic whole. Logistics engineering professional course system design for engineering education accreditation standard, it generally consists of the natural sciences, humanities, professional basic and professional courses etc., and the proportion of practice teaching should meet the standard of the training scheme.

Ability training should be considered first when the curriculum of logistics engineering is programmed .We can discern the competency-based knowledge point, then the curriculum system can be built based on it. The logistics engineering curriculum system will be optimized considering the new requirement of the internet + background. At the same time, the idea of project driven will be integrated into the design of the system. As we talked about above, logistics engineering will solve the engineering problems one by one, so the public basic courses of the curriculum system should be the courses of fundamental of natural science. Professional basic courses and the professional courses include the management courses and engineering basic courses, and all these courses constitution will make a difference when we want to optimize the curriculum system. In a word, the new curriculum system is designed under the guidance of the system theory, and the actual situation of the school at the same time is considered at the same time.The constration of the systen is showed in Figure.1.

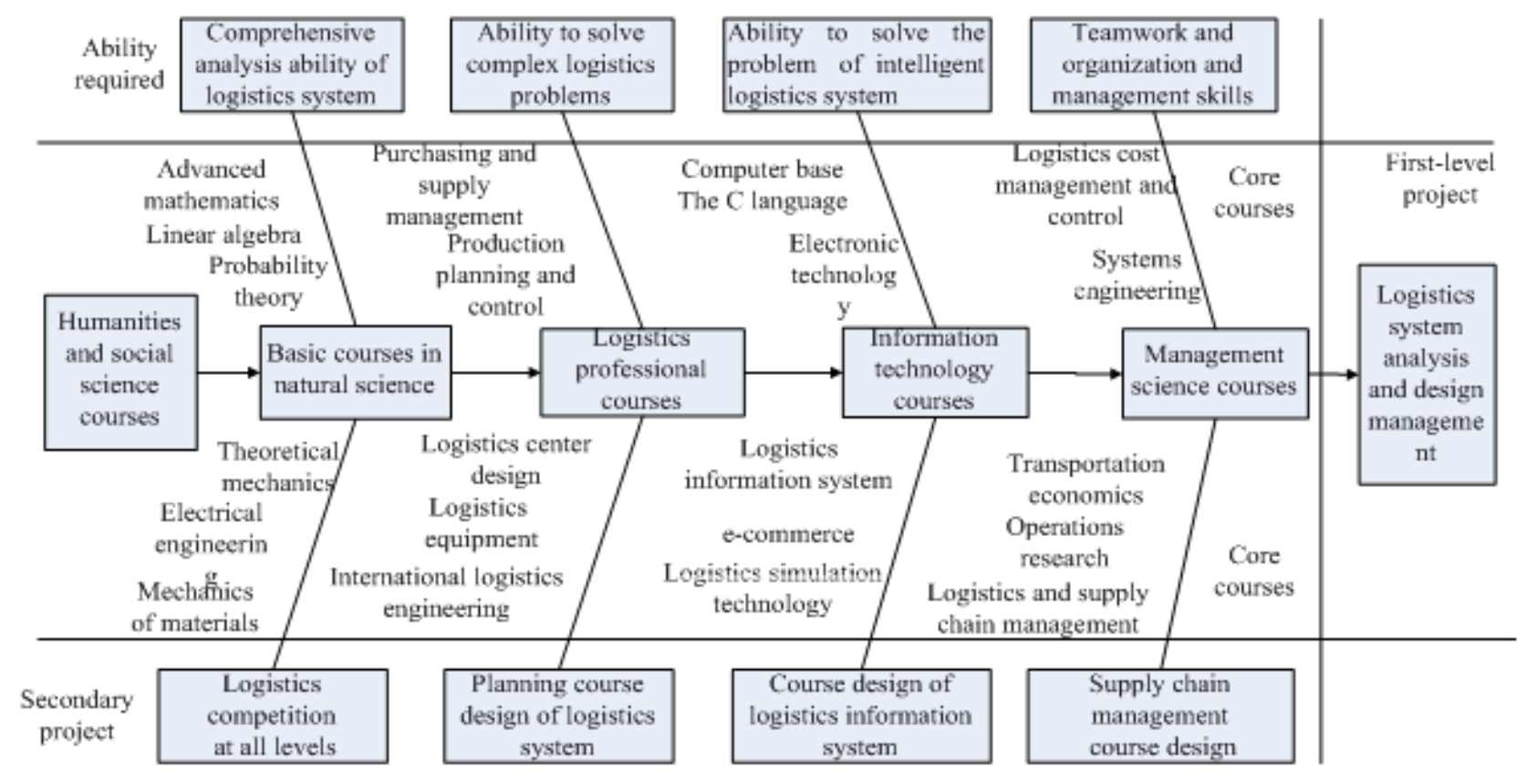

Figure. 1 Curriculum System of Logistics Engineering Talents Training

\section{Establishment of Practical Teaching System}

Under internet + background, the practical teaching of e-commerce logistics should be strengthen first in practical training of logistics engineering ,then the combination of professional teaching and practice contents is suggested to cultivate students' practical ability and innovative sprite. The systems of practical teaching are programmed according to the goal of the training program and the relative requirements of ability training are considered at the same time.

In order to improve the logistics engineering graduates' practice ability and the ability to solve the problem logistics system,the integration of the logistics engineering practice teaching system is put forward. It should be suggested to strength the construction of the university-enterprise cooperation platform for improving the internship environment,at the same time, it is necessary to encourage the students to participate in all kinds of logistics competition to improve the ability of professional skills and teamwork sprite. The practice teaching system is mended when taking the target of meeting the ability training as the guiding principle, and consider the teaching of the major 
core at the same time.The practice teaching system concludes three parts, the first content is logistics cognition practice which can exercise the professional cognitive skills of the students.The second part is the courses designing of logistics information system, distribution planning, that will can improve the abilities of to solve the problem of logistics system. The third item is the professional experiment and competition that can exercise the teamwork ability of the students. The integration of practice teaching system is thus formed, it is shown in Figure.2.

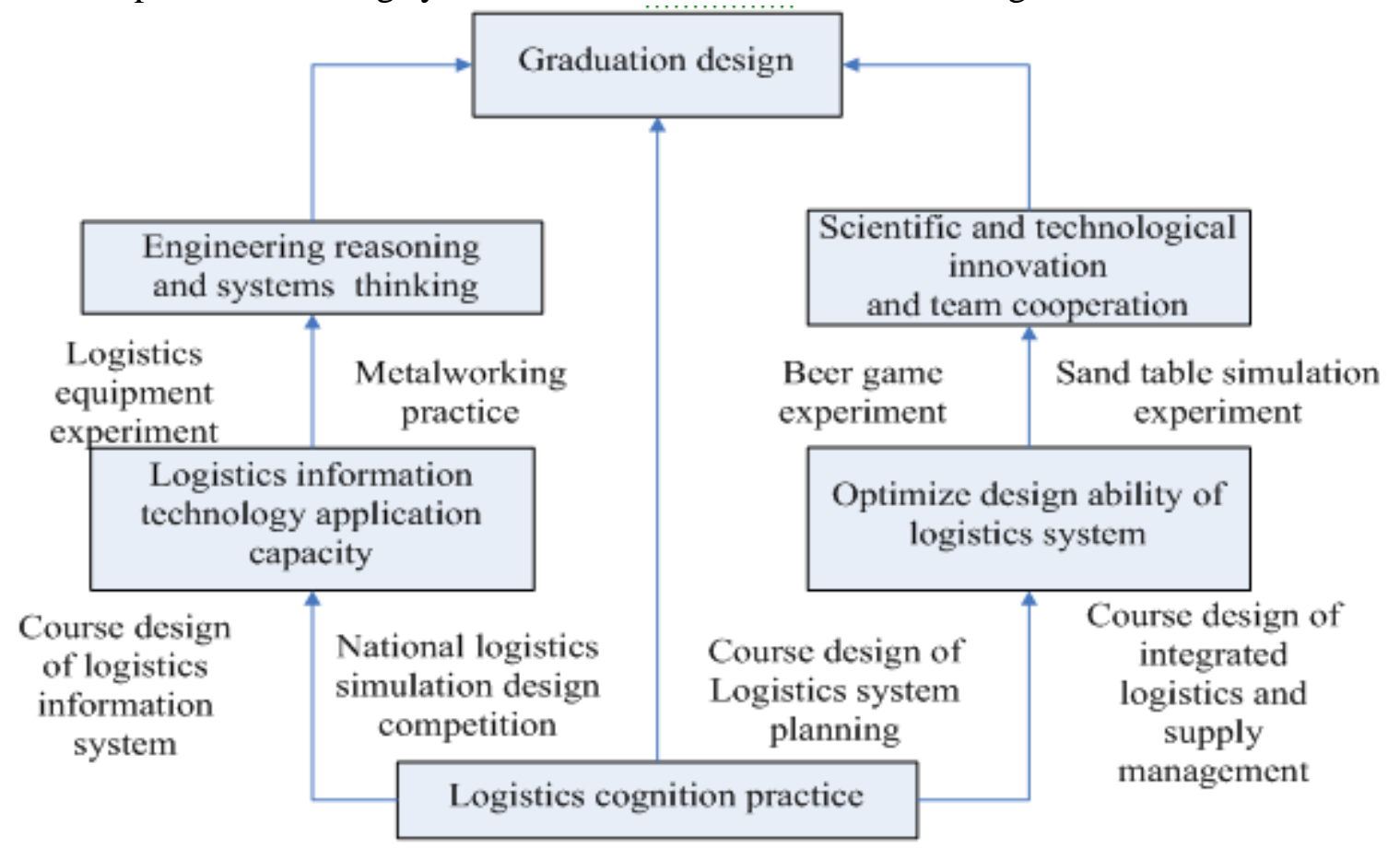

Figure. 2 Practice Training System of Logistics Engineering Talents

\section{Summary}

(1) The professional abilities of logistics talents are analyzed first on the base of investigation to the environmental requirements. The skills to solve the engineering problem and the ability to program and manage a logistics system should be strengthened in the training of logistics talents.

(2) The logistics engineering curriculum system is optimized considering the new requirement of the internet + background. At the same time ,the ideas of project driven are integrated into the design of the system.

(3) The integration of the logistics engineering practice teaching system is put forward, according the goal of the training program.It is not only a means to test the courses learning, but also an important measure to ensure the learning effect of the courses.

\section{Acknowledgement}

This research was financially supported by the Second Teaching Reform and Teaching Quality Evaluation Research Project grant funded by the Liaoning Education Evaluation Association (Project Number: PJHYYB17003) and 2017 Logistics Teaching and Reform Research Project grant funded by the China Society of Logistics (Project Number: JZW2017112 ).

\section{References}

[1]Fu Peihua, The exploration and practice of the construction of logistics management professional teaching organization,J. China Logistics \& Purchasing.2014(9)70—73 .

[2]HuHui, Zhang JingBo, The evaluation of university practice teaching system in the mode of 
innovative talent cultivation,J.Logistics Engineering and Management.2017(1)156—158 .

[3]Zhang Ying, Exploration and practice of innovative logistics personnel training, J. China management informationization. 2012(8)112-113 .

[4]Ma Jian and Li Xiao xia, Logistics undergraduate course system and teaching materials construction thinking ,J. Logistics engineering and management.2009(2)111-113.

[5]Li Li, On the demand and cultivation of logistics talents in China - based on the construction Angle of undergraduate logistics ,J. Logistics technology.2009(2)58-61 .

[6]Zhang Xufeng, The demand of logistics enterprises and the analysis of the training mode of logistics specialty in universities,J.Logistics engineering and management.2009(8)53—54. 